\title{
Design, Implementation and Evaluation of Proposal Writing Module Through Blended and Face to Face Learning Methods
}

\author{
Maryam Tarashchin, ${ }^{1}$ Rita Rezaee, ${ }^{2,}$ and Nahid Zarif Sanaiey ${ }^{3}$ \\ ${ }^{1}$ Comprehensive Center of Excellence for Electronic Learning, Shiraz University of Medical Sciences, Shiraz, IR Iran \\ ${ }^{2}$ Quality Improvement in Clinical Education Research Center, Shiraz University of Medical Sciences, Shiraz, IR Iran \\ ${ }^{3}$ Department of E-learning, Virtual School, Center of Excellence for e-Learning in Medical Sciences, Shiraz University of Medical Sciences, Shiraz, IR Iran \\ "Corresponding author: Rita Rezaee, Quality Improvement in Clinical Education Research Center, Shiraz University of Medical Sciences, Shiraz, IR Iran. E-mail: \\ rita_rezaee@yahoo.com
}

Received 2016 October 29; Accepted 2016 December 20.

\begin{abstract}
Background: Blended learning means using more than one method, strategy, technique, and medium in education to provide content and training materials. This method can affect student's learning owing to its flexibility and ability to use advantages of both face to face and e-learning methods. The aim of this study was to compare the effects of two methods of blended and face to face learning on the knowledge and performance of master's degree students of Shiraz University of Medical Sciences.

Methods: This research is a quasi-experimental study designed as pretest/posttest, which was conducted on 60 students. Based on the criteria, the selected students were randomly divided into two groups of 30 individuals to receive either blended or face to face learning. Data were collected at pretest and posttest using questionnaires and checklists. The acceptable significance level was set at $0.05(\alpha=0.05)$. Face and content validity of the questionnaire and checklist were assessed by four professors in the field of education. Reliability of the questionnaire and checklist was assessed using Cronbach's alpha, which gave the values of 0.72 and 0.7 , respectively. Data were analyzed through paired and independent t-tests in SPSS version 19.

Results: Results showed that the increases in pretest scores compared to posttest scores were significantly higher in the blended learning group than the face-to-face learning group $(\mathrm{P}<0.05)$. The score of the blended learning group also showed a significant increase compared to the other group $(\mathrm{P}<0.05)$.

Conclusions: If the methods, techniques, and educational media are used in the right place (according to the target group) and the right way, it can help improve and facilitate learning.
\end{abstract}

Keywords: Blended Learning, Research Proposal, Evaluation, E-Content, Multimedia

\section{Background}

One of the revolutions in the field of education is modern information and communication technologies which have provided the facility of exchanging information and long-distance connection instead of face to face educational systems. This approach has changed teaching and learning continuously, so that it encourages educational systems to utilize blended learning which had merely been used as a stand-alone approach (use of face to face training and/or distance education system). The term of blended learning generally means the use of both online and offline media in a program or course along with the face-to-face method to support learners (1).

To introduce blended learning, it must be said that there has been a tendency toward blended learning and training perhaps in the last 30 years (2). This educational method was first raised as the second wave of virtual education in 2003 by Marsh et al. (3).

In Rovai and Jordan opinion, half-face learning is a kind of flexible approach in training programs which is com- posed of learning at different times and places to support some of the features of virtual presence in training offers (4). Learning communities are able to put new multidimensional relationships (personal and academic) with learners in learning concepts so that being extensible beyond time, space, and limited courses (5).

Kenrad reported that combining virtual and face to face communications extends the flexibility of educational media and provides mutual relations among studentstudent, student-teacher and student-content in both virtual and physical environments.

Grisson and colleagues demonstrated that face to face learning experience is more teacher-oriented, whereas virtual learning experiences are more knowledge-oriented (learner-oriented). They stated that the experience of face to face education and transmission of information from teacher at the same time along with virtual learning can be a complementary learning process. Blended learning is a solution which includes face to face and online features. This method combines different educational methods, media, experiences, training and information components as 
well as synchronous and asynchronous learning and selfcentered learning (6).

Nowdays in traditional universities in the world, learning through blended approach has found a special place. Universities can use the principles of this approach to enhance the quality of their education, which in turn would improve the effectiveness and credibility of learning environments (7).

By expressing the importance of training on blended style, Ruiz stated that e-learning should not be a substitute for classroom instruction, but should be used complementarily with other methods. Vaughan and Garrison believe that not only the integration of e-learning with face to face method will enhance learning but also the interaction and satisfaction will br increased in this way. Thiele acknowledged that learners will have access to more information in this method and take responsibility for their learning. In addition, they have access to content at any time, so this method makes data accessibility much easier (8). In blended approach, education is done with holistic attitude towards learner by taking his/her personal characteristics such as beliefs, attitudes, knowledge, skills and mental abilities into consideration (4).

In other words, blended learning makes learning flexible for teachers and students. The integration of physical and virtual environments makes teacher and student both as learners, but this will be more effective in case of institutional support through the provision of vocational training and the opportunity to redesign courses (9).

Jahedi in his article has defined features of a successful semi-random model (blended) quoted from Martin: it includes a preliminary session, weekly meetings in Virtual Forum (Chat), synchronous and asynchronous discussions, sending email and a final face to face meeting with final exam (10).

Results of studies show that applying blended learning enhances students' learning.

For example, in this study showed the effectiveness of combined face to face and online learning (half-face or blended approach) amonge 40 students in knowledge, skills and satisfaction after the training course. They concluded that a combination of face to face and online learning can probably have acceptable effectiveness in education (11).

From the perspective of Zolfaghari et al., the blended education system is applied for its flexibility in learning process and ability to exploit the advantages of both face to face and electronical methods of learning. Therefore, it can affect learning and satisfaction of learners. They suggested more enhanced interaction and motivation in e-learning part of blended learning in order to achieve more success in this area (8).
In another study, Horatiu Catalano performed an educational course using blended learning method on adults. In this study, a variety of traditional learning methods was combined with online learning while face to face training sessions were tried to make challenges for online courses. Time management was also highly regarded. Based on responses from 150 participants who were teachers, the following results were obtained: educational programs using blended method generally promot adult education and specifically increase the productivity of continuing educational programs for teachers by creating a new educational method. However, there were shortcomings and problems in the implementation of this program, such as lack of cooperation from some of the participants in completing the questionnaires, the impossibility of generalizing the results of the study because of the limited number of participants, and so on.

Despite these limitations, as it seems, this study indicated an increase in the quality of educational programs for professional development. It also promoted the professional training programs for employees' evaluation system. It was shown that in addition to scientific knowledge of instructor/professor, having the necessary skills in technology also plays an important role in the success of any blended educational program (12).

In another study, Utku Kose according to the target group designed the blended model of learning based on web 2 technologies and found similar results. He concluded that students can learn math topics better by using the designed model. The researcher believes based on the results of this study that a blended learning model is suitable for use in different courses. In addition, other web 2 technologies like widgets and collaborative editing tools can enhance the effectiveness of online learning (13).

However in some studies, the effect of learning in both kinds of education has been the same. For example, Sonia Ramezani studied the effect of multimedia teaching and lecture on student's academic motivational achievement in Arabic course. Accordingly, there was no difference between the two groups in academic achievement motivation (multimedia and speech) (14). Saeedi Nejat and Vafaee Najar believe that blended learning can not be the dominant method in university education because exsisting facilities do not respond to this type of education (11). In fact, they introduced the lack of facilities as a factor reducing the effect of this educational method and its universality.

Now with regard to the raised issues, the purpose of this study was to examine the effectiveness of teaching proposal writing course using blended and face to face learning methods and their impact on student attendance and performance in Shiraz University of Medical Sciences.

This study intends to answer the following questions: 
1. Is the level of knowledge (scores) is different among students in blended and face to face learning groups before training?

2. Is the level of knowledge (scores) is different among students in blended and face to face learning groups after training?

3. Is performance (final evaluation) of students is different in blended and face to face learning groups after training?

\section{Methods}

This was a quasi-experimental study with pretestposttest design that deals with design, implementation, and evaluation of proposal writing module using blended and face to face learning methods among students of Shiraz University of Medical Sciences in 2015. The statistical population comprised all students of Shiraz University of Medical Sciences. According to the results of previous similar studies and taking into consideration the type of error and test power of 0.8 and significance level of 0.05 , a sample size of 30 students in each group (60 students in total) was determined. A list of volunteers was prepared following the announcement for participation in the training module. Based on the criteria, the participants were randomly divided into two groups of blended and face to face learning.

Inclusion criteria for this study included: having basic familiarity with computer, having access to the internet, and being graduate students not passing the research method course. Exclusion criteria included: absence in more than $20 \%$ of sessions, unwillingness to stay in the research project, and withdrawal of the study and training courses.

In order to comply with ethical considerations, confidentiality of the participants' responses in questionnaires and the possibility of withdrawal from the study were assured. In order to encourage and motivate participants to continue attending the training module, a certificate was presented to them from the medical education development center at the end of the module.

The project was implemented using two methods of blended and face to face learning, which are described in the following procedure:

The blended learning method was performed in 3 main stages (design, implementation, and evaluation). In the first stage (design), the curriculum and electronic content (interactive multimedia) were designed and uploaded on a learning management system. In the second phase (implementation) with regard to the syllabus of the blended learning, meetings were held for referrals, delivery of content (using multimedia educational CD), determining the relationship between students and teachers and teacherassistants, completing the pretest (to assess the knowledge of students before starting the module), and having the students fully apprised of the program.

Then, according to the schedule, the final session was held at the due date as face to face and virtual (online) workshops. In the third stage (evaluation), the post-test questionnaire was sent to the students through learning management system a month after the final session. All the participants completed the follow-up questionnaires and sent them back through the system to the researcher.

Skill and ability of students in writing proposal were assessed and scored by two assessors using checklists.

The checklist contained items designed according to the "student participation in group discussions" and "number of responses sent to practical assignments".

It is noteworthy that the total score was the sum of knowledge scores (post-test), participation scores and skills and ability scores and used to evaluate the performance of students in the module.

In face to face learning group, like blended learning, study was performed in 3 main phases (design, implementation, and evaluation). In the first stage (design), the lesson plan of one-day workshop was set up and educational content of the workshop was developed in PowerPoint format. Then, the schedule for the workshop was emailed to the students. In the second phase (implementation), during a one-day workshop the program was implemented by professors on the students. Before beginning the workshop, the pretest was done. The material and content provided in the form of PowerPoint slides as well as a printed copy of the crude proposal form were delivered to the students. Some projects were carried out in collaboration with the students and the results were evaluated. One month after the end of the workshop, post-test questionnaire was sent as a follow-up email to be filled out by thestudents and returned backthrough the email. In the third phase (evaluation), like blended learning group, one month after the end of the training module, post-test questionnaires were distributed.

Student's skills and participation scores were measured by the same checklist used for the blended learning group.

Like blended learning group, for evaluating student's performance in this module, the student's total score was the sum of knowledge (posttest), participation, skill and ability scores.

Data were collected using demographic form, checklist, and questionnaire.

1. The questionnaire was used to assess the impact of education on knowledge before and after training (pretest and posttest). This questionnaire contained 23 questions 
in the form of multiple choices, true and false, and matching design. All questions were designed based on learning objectives. For scoring the questions, score one was designated for each correct answer and score zero for each incorrect answer or no answer. The validity of this tool was evaluated and approved by a group of four professors and experts in the field of education.

2. The checklist was used by the researcher to observe and evaluate the participation of students. The checklist examined the criteria of "student participation in group discussions" and "student's responses to practical tasks". To assess the level of learners participation in group discussions, a three-point scale (yes, partly, and no) was considered. If all the professors' questions were responded, learners scored 10 and if a number of questions were responded, they scored 5, and if no question was answered, they received score 0 . To measure the participation, the number (quantity) of responses to practical skill assignments as well as learning assignments (including 13 essay questions and 1 multichoice question) were counted and their scores were calculated from the maximum score of 14. To confirm the face and content validity of the checklist, opinions and viewpoints of 4 professors and experts in this field was used. After making necessary reforms, the validity of the checklist was confirmed. Also, the reliability of the checklist was calculated as 0.83 on the basis of Cronbach's alpha coefficient.

3. Another checklist was employed to determine the capability and skills of students in drafting the proposal components correctly through 18 questions. Therefore, the quality of writing proposals was assessed. In order to confirm the content and face validity of the checklist, the opinions and viewpoints of a group of four professors and experts in the field of education were used and after making necessary reforms, the validity of the checklist was confirmed. Also, the reliability of the checklist was calculated as 0.7 based on Cronbach's alpha.

In this study, there are some restrictions that are mentioned below:

1. Coordination with the Department of Education of several colleges about student's participation in the educational module.

2. Adjustment of the module's time so that the maximum number of students could attend the module.

3. Getting the participation of students due to the voluntary module.

In order to comply with ethical issues, this study emphasized technical and educational support of participants in the module throughout the program. Also, the results were presented to all the participants and other stakeholders such as the center of excellence in e-learning, educational Affairs. At the end, educational CDs were presented to the participants in the face to face learning group. Also, the present study with the moral code of 92666946-CT was reviewed and approved by the ethics committee of the faculty of Medicine, Shiraz University of Medical Sciences.

\section{Results}

In this section, collected data were classified and analyzed in two separate parts. First, descriptive analysis of data is reported in Table 1 (including age, gender, marital status and employment status of students participating in the module) and then inferential analysis of data (in response to study questions) is summarized in Tables 2 to 6.

Table 1. Distribution of Frequency in Personal and Demographic Characteristics of the Students Participating in Training Module ${ }^{\mathrm{a}}$

\begin{tabular}{|ccc|}
\hline Subjects & Values & Number \\
\hline Age & & \\
\hline & Mean \pm SD & \\
& Range & $30.97 \pm 25.5$ \\
\hline Sex & & $24-45$ \\
\hline & Female & \\
\hline Male & $50(83.3)$ \\
\hline Marital Status & $10(16.7)$ \\
\hline Single & $40(66.7)$ \\
\hline Married & $20(33.3)$ \\
\hline Employment Status & \\
\hline Employed & $40(66.7)$ \\
\hline Unemployed & $20(33.3)$ \\
\hline
\end{tabular}

${ }^{\mathrm{a}}$ Values are expressed as No. (\%).

Table 1 shows demographic and personal characteristics of students participating in this module. As can be seen, from a total of 60 students participated in the study 50 were women (83.3\%) and 10 (16.7\%) were male. The age range of subjects was 24 to 45 years, the mean age was 30.97 years and the standard deviation was 5.25. In total, 33.3\% of the subjects were married and $66.7 \%$ were single. In addition, $66.7 \%$ of the subjects were employed and $33.3 \%$ were unemployed (Table 1 ).

Table 2 in response to the first question of the research (does the average level of knowledge in students vary before and after training in blended and face to face learning groups?) shows that based on paired t-test results, the mean scores of student's knowledge in face to face learning group before and after training have had a significant 
difference $(\mathrm{P}<0.001)$. The mean scores of student's knowledge also in face to face learning group were significantly different before and after training $(\mathrm{P}<0.001)$. This means that both groups were at the same level in terms of subjects' knowledge. In other words, knowledge in one group has not been superior to that of the other group.

In response to the second question (Does the average level of students' knowledge vary in blended and face to face learning groups after training?) and based on data from Table 3, the results of independent t-test regarding the comparison of the scores of students in blended and face to face learning groups before training showed that the mean scores were not significantly different $(\mathrm{P}=0.12)$. These results indicate that both groups were at the same level of knowledge before training.

However, the results of independent t-test regarding the comparison of the scores of student's knowledge in blended and face to face learning groups after training showed that the mean scores were significantly different $(P$ $<0.001)$. Since the mean score in blended learning group is higher than that of face to face learning group after training, it is implied that teaching in blended style had greater impact on increasing the knowledge of students.

In response to the third question (Does the performance score (in final evaluation) of students in two blended and face to face learning groups change after training?) it should be noted that the student's performance score (which is the index of the final evaluation in this module) is the sum of knowledge score (in posttest), participation score, and skill score. Skills and ability scores are first compared in Table 4 and then, participation scores of students in both blended and face to face learning groups are presented in Table 5. Finally, the study data on performance of students in both groups are compared in Table 6.

Based on the data in Table 4, the results of independent t-test to compare mean scores of student's skills and ability in blended and face to face learning groups before training show that the difference in the mean score was not statistically significant $(P=0.96)$. These results indicate that skills and ability score of both groups before training was at the same level.

However, the results of independent t-test to compare the mean scores of skills and ability of students in blended and face to face learning groups after training show that the mean scores are statistically different between the groups $(P=0.02)$. Given that the mean score of skill in blended learning group is higher than that of face to face learning group after training, it can be inferred that training in blended manner have a greater impact on increasing skills and ability of students in writing research proposals.

Based on the data in Table 5, the results of independent t-test to compare the mean scores of student participation in blended and face to face learning group show that there was a significant between-group difference after training $(\mathrm{P}=0.029)$. Given that the mean score of participation in blended learning group is higher than that of face to face learning group, it is implied that the use of various interactive methods in blended learning increased student's participation during the module.

Based on the data in Table 6, independent t-test shows a significant difference in student's performance between the groups undergoing two different educational methods (in final evaluation) at $\mathrm{P}=0.001$. This means that blended learning group has had more satisfying performance in the final evaluation.

\section{Discussion and Conclusion}

In this study, the effect of training on proposal writing through blended and face to face modules on knowledge and performance of students was studied. Based on the findings, the blended mode of learning had a greater impact on increasing students' knowledge. These findings are consistent with the results of Jafari's study in which lecture and blended learning styles were compared in terms of the extent of learning. He believes that blended learning with strengthening internal motivation and increasing student satisfaction can lead to promoted learning (15). Also, Katie J. Soda and colleagues in a research concluded that compared to in-person courses, blended learning increased scores and understanding of learners in terms of achievement of the objectives of the course (16). In addition, Ron Stone and Dennis York found from their study to evaluate the relationship between the learners's understanding of education using two blended and face-toface methods that the blended method resulted in higher scores (17). The findings of this research are consistent with the results reported by Karamizadeh and colleagues in comparison of the effects of blended and virtual education on learning and satisfaction. A significant association was also found between pretest and posttest scores while post-test score was significantly higher than pre-test score (18).

In studying the impact of education using blended learning style on students' performance, the findings suggested that various interactive methods of teaching in blended manner of learning have greater impact on increasing skills, ability, and participation of students in writing research proposals.

This result is in line with those of Zolfaghari (8), Horatiu Catalano (12), Utku Kose (13) and Zarif Sanaee (19) and not in line with the findings of Saeedi Nejat, Vafaee Najjar (11) and Ramazani (14). Perhaps the cause of inconsis- 
Table 2. Comparison of the Level of Student's Knowledge in Blended and Face to Face Learning Groups Before And After Training (Separately for Each Group)

\begin{tabular}{lcc}
\hline Statistical Indicators & Knowledge Score Before Training & Knowledge Score After Training \\
& Mean \pm SD & Mean \pm SD \\
\hline Blended learning group & $21.73 \pm 3.47$ & $32.63 \pm 2.17$ \\
face to face learning group & $20.43 \pm 2.90$ & $29.96 \pm 3.14$ \\
\hline
\end{tabular}

Table 3. Comparison of the Level of Student's Knowledge in Blended and Face to Face Learning Groups Before and After Training

\begin{tabular}{|c|c|c|c|}
\hline \multirow[t]{2}{*}{ Statistical Indicators } & Blended Group & Face to Face Group & P Value \\
\hline & Mean \pm SD & Mean \pm SD & \\
\hline Knowledge score before training & $21.73 \pm 3.47$ & $20.43 \pm 2.90$ & 0.12 \\
\hline Knowledge score after training & $32.63 \pm 2.17$ & $29.96 \pm 3.14$ & $<0.001$ \\
\hline
\end{tabular}

Table 4. Comparison of Student's Skill Score (in Final Evaluation) in Blended and Face to Face Learning Groups Before and After Training

\begin{tabular}{lcc}
\hline Statistical Indicators & Blended Learning Group & Face to Face Learning Group \\
Skills and ability scores & Mean \pm SD & Mean \pm SD \\
\hline Skills scores before training & $9.13 \pm 2.84$ & $9.16 \pm 2.45$ \\
Skills scores after training & $28.37 \pm 3.337$ & $26.67 \pm 2.023$ \\
\hline
\end{tabular}

Table 5. Comparison of Student's Participation Scores in Blended and Face to Face Learnig Groups After Training

\begin{tabular}{lcc}
\hline Statistical Indicator & Blended Learning Group & Face to Face Learning Group \\
& Mean \pm SD & Mean \pm SD \\
\hline Participation scores & $21.03 \pm 3.508$ & $18.53 \pm 5.002$ \\
\hline
\end{tabular}

Table 6. Comparison of Student's Performance Score (in Final Evaluation) in Blended and Face to Face Learning Groups After Training

\begin{tabular}{lcc}
\hline Statistical Indicators & Blended Learning Group & Face to Face Learning Group \\
& Pean Value \pm SD & Mean \pm SD \\
\hline $\begin{array}{l}\text { The comparison of final perfromance score between groups (Knowledge scores } \\
\text { (posttest)+ participation scores + skills and abilitr scores) }\end{array}$ & $82.03 \pm 6.89$ & $75.47 \pm 7.02$ \\
\hline
\end{tabular}

tency with the former study is the difference in technological possibilities of the two study groups. Also, the cause of disagreement with the results of the latter study is probably the use of a variety of presentation methods in the employed models. This means that in the present study, in addition to design and presentation of content in multimedia format, other methods such as virtual classrooms, learning management system, as well as face to face meetings were used.

As can be seen in most of the papers in e-learning field, blended learning is recognized as an effective, enjoyable, supportive, flexible, and encouraging approach for learners. However, these factors are not sufficient enough to create a successful learning environment. In other words, in order to create a positive and effective learning environment, teachers who use online learning environment should encourage students to participate more in this environment and they should look for the ways through which more participation be created in terms of social interaction among students. Moreover, devices such as tablets, smartphones, and touchscreens will be more popular in near future, which makes it necessary to study the implementation of blended learning courses. By increasing technological innovations, new types of blended learning are created and training will be coming out with different technologies. But the key question is "how should 
we organize the learning environment in order to learn more?" The answer is that we need to be integrated into models of constructivism and collaborative blended learning environment and foster creative and curious students who read, write, and create (20).

In general, students in blended learning group have been able to obtain better results in scores of knowledge and practice owing to the benefits of this method. As a result, using this method has a positive effect on increasing knowledge and performance of the students.

\section{Footnotes}

Authors' Contribution: Study concept and design, analysis and interpretation of data, drafting of the manuscript, critical revision of the manuscript for important intellectual content, statistical analysis, Rita Rezaee, Maryam Tarashchin, and Nahid Zarif Sanaiey

Conflict of interest: None declared.

\section{References}

1. de Jong N, Savin-Baden M, Cunningham AM, Verstegen DM. Blended learning in health education: three case studies. Perspect Med Educ. 2014;3(4):278-88. doi: 10.1007/s40037-014-0108-1. [PubMed: 24458338].

2. Hainey K, Kelly LJ, Green A. A blended learning approach to teaching CVAD care and maintenance. Br J Nurs. 2017;26(2):S4-S12. doi: 10.12968/bjon.2017.26.2.S4. [PubMed: 28132565].

3. Atkins S, Yan W, Meragia E, Mahomed H, Rosales-Klintz S, Skinner $D$, et al. Student experiences of participating in five collaborative blended learning courses in Africa and Asia: a survey. Glob Health Action. 2016;9(1):28145. doi: 10.3402/gha.v9.28145. [PubMed: 28156883].

4. Prescott WJ, Woodruff A, Prescott GM, Albanese N, Bernhardi C, Doloresco F. Introduction and Assessment of a Blended-Learning Model to Teach Patient Assessment in a Doctor of Pharmacy Program. Am J Pharm Educ. 2016;80(10):176. doi: 10.5688/ajpe8010176. [PubMed: 28179725].

5. Garrison DR, Vaughan ND. Blended learning in higher education Framework, principles, and guidelines. John Wiley \& Sons; 2008.

6. Baglien VG. Implementation of blended instruction: A case study of secondary family and consumer sciences. Iowa: Iowa State University; 2009.
7. Neshat Avar R, Jahedi F, Kajuri J, editors. Current position and role of blended learning in medical education [In Persian]. Proceedings of the 2nd Conference of E-Learning in Medical Education. 2009; Tehran. Mashhad: Ferdowsi University Publications.

8. Zolfaqari M, Sarmadi M, Negarandeh R, Zandi B, Ahmadi F. Studying the satisfaction of Nursing and Midwifery students and teachers from applying blended learning system [In Persian]. Iran J Nurs Res. 2010;3(10-11):99-109.

9. Bliuc AG. Blended/hybrid learning Available from: http://www. Grayharriman.Com/Blended_Learning.Htm.

10. Jahedi A, Mesbah A. The effect of face-to-face and blended education of general prerequisite courses on post-requisite courses for technical students [In Persian]. Mag Elearn Dist Acad. 2015;5(4):62-72.

11. Saeedinejat $S$, Vafaeenajar A. The effect of e-learning on students' educational success [In Persian]. Iran J Med Educ. 2011;11(1):1-9.

12. Catalano H. The Opportunity of Blended-learning Training Programs in Adult Education - Ascertaining Study. Procedia Soc Behav Sci. 2014;142:762-8. doi: 10.1016/j.sbspro.2014.07.612.

13. Köse U. A blended learning model supported with Web 2.0 technologies. Procedia Soc Behav Sci. 2010;2(2):2794-802. doi: 10.1016/j.sbspro.2010.03.417.

14. Ramazani SM. The effect of multimedia vs. Lecture-based education on educational achievement motivation (intrinsic and extrinsic) in Arabic course in tehran virtual schools [In Persian]. Educ Psychol. 2011;7(21):119.

15. Jafari M. Comparison of lecture and blended teaching methods on learning and satisfaction of medical students in biochemistry course [In Persian]. Iran J Med Educ. 2012;12(7):488-97.

16. Suda KJ, Sterling JM, Guirguis AB, Mathur SK. Student perception and academic performance after implementation of a blended learning approach to a drug information and literature evaluation course. Curr Phar Teach Learn. 2014;6(3):367-72. doi:10.1016/j.cptl.2014.02.017.

17. Owston R, York D, Murtha S. Student perceptions and achievement in a university blended learning strategic initiative. Internet High Educ. 2013;18:38-46. doi: 10.1016/j.iheduc.2012.12.003.

18. Karamizadeh Z, Zarifsanayei N, Faghihi AA, Mohammadi H, Habibi $M$. The study of effectiveness of blended learning approach for medical training courses. Iran Red Crescent Med J. 2012;14(1):41-4. [PubMed: 22737553].

19. Zarif Sanaiey N. The comparative study of the effectiveness of using e-learning, blended learning and presence learning in continuous medical education. World J Med Sci. 2014;10(4):488-93.

20. Güzer B, Caner H. The past, present and future of blended learning: an in depth analysis of literature. Procedia Soc Behav Sci. 2014;116:4596-603. 